\title{
Processing and Structure of Carbon Nanofiber Paper
}

\author{
Zhongfu Zhao, ${ }^{1}$ Jihua Gou, ${ }^{1}$ and Aurangzeb Khan ${ }^{2}$ \\ ${ }^{1}$ Department of Mechanical, Materials and Aerospace Engineering, University of Central Florida, Orlando, FL 32816, USA \\ ${ }^{2}$ Department of Electrical and Computer Engineering, University of South Alabama, Mobile, AL 36688, USA
}

Correspondence should be addressed to Jihua Gou, jgou@mail.ucf.edu

Received 3 November 2008; Accepted 24 February 2009

Recommended by Alan K. T. Lau

\begin{abstract}
A unique concept of making nanocomposites from carbon nanofiber paper was explored in this study. The essential element of this method was to design and manufacture carbon nanofiber paper with well-controlled and optimized network structure of carbon nanofibers. In this study, carbon nanofiber paper was prepared under various processing conditions, including different types of carbon nanofibers, solvents, dispersants, and acid treatment. The morphologies of carbon nanofibers within the nanofiber paper were characterized with scanning electron microscopy (SEM). In addition, the bulk densities of carbon nanofiber papers were measured. It was found that the densities and network structures of carbon nanofiber paper correlated to the dispersion quality of carbon nanofibers within the paper, which was significantly affected by papermaking process conditions.
\end{abstract}

Copyright (c) 2009 Zhongfu Zhao et al. This is an open access article distributed under the Creative Commons Attribution License, which permits unrestricted use, distribution, and reproduction in any medium, provided the original work is properly cited.

\section{Introduction}

A variety of nanoparticles have been incorporated into polymer resins to make nanocomposites for a wide range of applications [1, 2]. Among them, carbon nanotubes and carbon nanofibers have attracted significant research interests due to their unique characteristics and properties such as high strength and modulus, low density, high surface area, good chemical stability, high electrical and thermal conductivity, and fire resistance. Although there are different processing techniques to fabricate polymer nanocomposites, they are mainly divided into three categories: (a) solution processing [3-13], (b) melt mixing [14-17] using a batch mixer or continuous device such as an extruder, and (c) in situ polymerization $[18,19]$. The mechanical and physical properties of polymer nanocomposites have large variations due to processing-related issues.

Generally, carbon nanotubes and carbon nanofibers consist of graphitic cylinders with diameters of 1-100 nm and high aspect ratios of a few micro lengths, leading to high van der Waals force between adjacent nanotubes or nanofibers. The high van der Waals forces and high aspect ratios with a combination of high flexibilities make the nanotubes and nanofibers easily aggregate. As a result, it is difficult to individually disperse the nanotubes or the nanofibers into polymer resins. The addition of a small amount of carbon nanofibers will also significantly increase the viscosity of the resin. Particularly during the processing of fiber-reinforced polymer composites, the resin flow through the fiber mats becomes very difficult. The fiber mats will also filter out the nanotubes and nanofibers during liquid molding process such as resin transfer molding and vacuum-assisted resin transfer molding $[20,21]$. In addition, the presence of the nanotubes or nanofibers can significantly modify the local crystallization behavior of polymer resins either through the direct polymer/particle interaction at the interface or the modification of temperature and stress field around and between the nanotubes or nanofibers.

A unique concept of making nanocomposites from carbon nanofiber paper has been explored [22-24]. This approach involves making carbon nanofiber paper through the filtration of the suspension of well-dispersed carbon nanofibers under controlled process conditions. Such a specialty paper has a uniform network structure formed through the entanglement of the nanofibers. The carbon nanofiber paper can be further integrated into traditional fiber reinforced composite laminates through liquid molding processes. The structural characteristics of carbon nanofiber paper such as pore size and orientation can significantly affect the penetration of polymer resins. In this study, the correlation between the morphologies and processing conditions of the paper was systematically studied. Specifically, 
the effects of different types of carbon nanofiber, solvent, dispersant, and acid treatment on the microstructures of carbon nanofiber paper were examined. The processing conditions were chosen to make carbon nanofiber paper with an optimum structure.

\section{Experimental}

Vapor-grown carbon nanofiber was supplied from Applied Sciences, Inc., Cedarville, Ohio, USA. Two types of carbon nanofibers were used: oxidized carbon nanofiber (OXCNF) and nonoxidized carbon nanofiber (NOXCNF). Compared to NOXCNF, OXCNF had more functional groups, such as hydroxyl group $(-\mathrm{OH})$ and carboxylic acid $(-\mathrm{COOH})$. The OXCNF and NOXCNF were rinsed with diluted nitric acid. The acid-treated carbon nanofibers were designated as RINOXCNF and RIN-NOXCNF. During the rinse of carbon nanofibers, OXCNF or NOXCNF was first stirred in $2 \mathrm{M}$ nitric acid at room temperature for 2 hours. The solution was then filtered through a $4 \mu \mathrm{m}$ polycarbonate membrane and rinsed with water until the nitric acid was completely removed. In this study, deionized water (WA), ethyl alcohol $(\mathrm{AL})$, and acetone $(\mathrm{AC})$ were used as solvents. The dispersant (DISPERBYK-191; BYK-Chemie, Wesel. Germany) was used to aid the dispersion of carbon nanofibers. The BYK had amine values of $20 \mathrm{mg} \mathrm{KOH} / \mathrm{g}$ and acid value of $30 \mathrm{mg}$ $\mathrm{KOH} / \mathrm{g}$ and could work through steric stabilization of carbon nanofibers.

Carbon nanofiber paper was fabricated by using the following procedures. The as-treated or as-received carbon nanofibers of $200 \mathrm{mg}$ were grinded by placing them into a mortar and adding a small amount of solvent. After grinding, they were transferred into $500 \mathrm{~mL}$ beaker. and $400 \mathrm{~mL}$ solvent was added. The suspension was sonicated using a high intensity sonicator for 20 minutes. After the initial sonication, both the solution and the probe were cooled down to room temperature. $1 \mathrm{~mL}$ BYK was then added to the suspension. The suspension was sonicated for another 20 minutes under the same condition. The asprepared suspension was allowed to settle overnight. $300 \mathrm{~mL}$ suspension at the upper level of the beaker was collected. The remaining $100 \mathrm{~mL}$ suspension containing some deposits was mixed with $200 \mathrm{~mL}$ solvent and sonicated for another 10 minutes. The carbon nanofiber paper was made by filtering the suspension through $0.4 \mu \mathrm{m}$ hydrophilic polycarbonate or hydrophobic Teflon membrane under a high-pressure filtration system. The carbon nanofiber paper was further dried in oven at $120^{\circ} \mathrm{C}$ for 2 hours. In this study, eight groups of samples were made under various combinations of different types of carbon nanofibers, solvents, BYK, suspension, or deposit, as shown in Table 1. The samples of carbon nanofiber paper were designated based on their processing conditions. For example, RIN-OXCNF-AC-SUSBYK represents that the sample was made from RIN-OXCNF suspension in acetone, which was dispersed with an aid of dispersant BYK. OXCNF, RIN-OXCNF, NOXCNF, and RINNOXCNF are four types of carbon nanofibers. Three types of solvents including water, alcohol, and acetone were used. SUS and DEP indicate the samples from the upper suspension or the deposit, respectively.

\section{Results and Discussion}

3.1. Effects of Solvents. OXCNFs were dispersed in water, ethyl alcohol, and acetone. It was found that OXCNF could be easily dispersed in water and alcohol but not well dispersed in acetone. The variations in the dispersion quality are due to the surface functional groups of OXCNFs. The suspension of OXCNFs in water and ethyl alcohol was stable. But carbon nanofibers easily agglomerated in acetone once the sonication was over. Both water and alcohol are more polar solvent than acetone. The oxidized carbon nanofiber has more functional groups such as $\mathrm{OH}, \mathrm{COOH}$, and so forth in the solution. Therefore, the interaction between the polar groups (i.e., $\mathrm{OH}$ groups on the nanofiber and $\mathrm{OH}$ groups of alcohol or water) leads to better quality of dispersion. Six samples of carbon nanofiber paper were made: OXCNFWA-SUS, OXCNF-WA-DEP, OXCNF-AL-SUS, OXCNF-ALDEP, OXCNF-AC-SUS, and OXCNF-AC-DEP. Figures 1(a)1(e) show the scanning electron microscopy (SEM) images of OXCNF-WA-SUS, OXCNF-AL-SUS, OXCNF-AC-SUS, OXCNF-WA-DEP, and OXCNF-AL-DEP, respectively.

Figures $1(\mathrm{a})$ and $1(\mathrm{~d})$ show the SEM images of OXCNFWA-SUS and OXCNF-WA-DEP, respectively. It can be seen that no large particles can be found in Figure 1(a). However, large particles can be clearly observed in Figure 1(d). The large particles came from the aggregates of carbon nanofibers. Carbon nanofibers with smaller diameters were closely packed in OXCNF-WA-SUS, which results in a higher bulk density of OXCNF-WA-SUS, as shown in Table 2. The metal catalyst particles can be found in both OXCNF-WASUS and OXCNF-WA-DEP.

Similar observation was made for OXCNF-AL-SUS and OXCNF-AL-DEP, as shown in Figures 1(b) and 1(e). It is difficult to individually disperse and separate carbon nanofibers, and the deposited carbon nanofibers became the aggregates. The difference between Figures 1(d) and $1(\mathrm{e})$ indicates that it was more difficult to separate carbon nanofibers in alcohol than in water. Larger carbon nanofiber aggregates can be found in Figuer 1(e). There are more carbon nanofibers with smaller diameters shown in Figure 1(a) due to better dispersion of carbon nanofibers in water. This observation also can be made by comparing their weights shown in Table 2. About $30.5 \mathrm{wt} \%$ carbon nanofibers were deposited in OXCNF-AL-DEP. Only about $25.5 \mathrm{wt} \%$ carbon nanofibers were deposited in water. From Figures $1(a)-1(c)$, OXCNF-WA-SUS had good network structure of carbon nanofibers, in which no large carbon nanofiber aggregates were formed, and individual nanofibers were closely packed within the paper. It seems that the structure of carbon nanofiber paper was better in OXCNF-AC-SUS than in OXCNF-AL-SUS.

3.2. Effects of Dispersant. In order to obtain better dispersion of OXCNFs in acetone, the dispersant, BYK, was used. For OXCNF-AC-SUS-BYK and OXCNF-AC-SUS, it was found 
TABLE 1: Sample identification and processing conditions.

\begin{tabular}{|c|c|c|c|c|}
\hline Sample ID & Type of carbon nanofiber & Type of solvent & Use of dispersant & Suspension or deposit \\
\hline OXCNF-WA-SUS & OXCNF & Water & & SUS \\
\hline OXCNF-WA-DEP & OXCNF & Water & & DEP \\
\hline OXCNF-AL-SUS & OXCNF & Alcohol & & SUS \\
\hline OXCNF-AL-DEP & OXCNF & Alcohol & & DEP \\
\hline OXCNF-AC-SUS & OXCNF & Acetone & & SUS \\
\hline OXCNF-AC-DEP & OXCNF & Acetone & & DEP \\
\hline RIN-OXCNF-AC-SUS & RIN-OXCNF & Acetone & & SUS \\
\hline RIN-OXCNF-AC-DEP & RIN-OXCNF & Acetone & & DEP \\
\hline RIN-OXCNF-AC-SUS-BYK & RIN-OXCNF & Acetone & DISPERBYK-191 & SUS \\
\hline RIN-OXCNF-AC-DEP-BYK & RIN-OXCNF & Acetone & DISPERBYK-191 & DEP \\
\hline RIN-OXCNF-WA-SUS & RIN-OXCNF & Water & & SUS \\
\hline RIN-OXCNF-WA-DEP & RIN-OXCNF & Water & & DEP \\
\hline NOXCNF-AC-SUS-BYK & NOXCNF & Acetone & DISPERBYK-191 & SUS \\
\hline NOXCNF-AC-DEP-BYK & NOXCNF & Acetone & DISPERBYK-191 & DEP \\
\hline RIN-NOXCNF-AC-SUS-BYK & RIN-NOXCNF & Acetone & DISPERBYK-191 & SUS \\
\hline RIN-NOXCNF-AC-DEP-BYK & RIN-NOXCNF & Acetone & DISPERBYK-191 & DEP \\
\hline
\end{tabular}

that less carbon nanofibers were deposited with the aid of the dispersant, as shown in Table 2. The dispersant or surfactant decreases the interfacial surface tension or surface energy of the solid phase like carbon nanofibers. Therefore, they can be relatively easily dissolved in the solvent. Under the same processing conditions, only $38.5 \mathrm{wt} \%$ of OXCNFs remained in the suspension for OXCNF-AC-SUS but $60.7 \mathrm{wt} \%$ of OXCNFs for OXCNF-AC-SUS-BYK. Large amount of OXCNFs were individually dispersed into acetone with the aid of BYK. Figure 2 shows the SEM images of OXCNF-AC-SUSBYK. Compared to Figure 1(c), Figure 2 clearly indicates that more uniform network structure was formed in OXCNFAC-SUS-BYK. In Figure 1(c), carbon nanofiber paper only consisted of straight OXCNFs with larger diameters. But there were some curved OXCNFs with smaller diameters in Figure 2. Therefore, the use of BYK could improve the dispersion of OXCNFs.

3.3. Effects of Acid Rinse. The diluted nitric acid was used to rinse carbon nanofibers. Figures 3 and 4 show the SEM images of RIN-OXCNF-AC-SUS-BYK, RIN-OXCNFAC-DEP-BYK, RIN-OXCNF-WA-SUS, and RIN-OXCNFWA-DEP. Compared to OXCNF-AC-SUS-BYK in Figure 2, Figure 3(a) shows uniform network structure without large OXCNF aggregates. The acid rinse improved the dispersion of OXCNFs within the paper consisting of short and small nanofibers. From Figure 1(a), it can be seen that short OXCNFs existed in bundles and filled the pores of carbon nanofiber paper. The OXCNF-WA-DEP only had $25.5 \mathrm{wt} \%$, but RIN-OXCNF-WA-DEP could reach up to $38.9 \mathrm{wt} \%$, as show in Table 2. Compared to Figure 1(d), Figure 4(b) shows more carbon nanofiber aggregates, although the size of carbon nanofiber aggregates in Figure 1(d) was much larger. It can be concluded that it is not necessary to treat OXCNFs with the acid rinse if the water is used as solvent. The acid rinse could improve the dispersion of carbon nanofibers in alcohol and lead to uniform network structure.

3.4. Effects of Carbon Nanofibers. There are very few active chemical sites on the surface of NOXCNFs. Therefore, it is extremely difficult to directly disperse NOXCNFs in water and acetone. The NOXCNFs were easily aggregated after the sonication. The filtered carbon nanofiber paper had very rough surface. The NOXCNFs were deposited quickly on the bottom of the beaker in water. The NOXCNF floccules were formed in acetone. In order to obtain a stable suspension of NOXCNFs, it is necessary to use the dispersant BYK in acetone. Figure 5 shows the morphologies of NOXCNF-ACSUS-BYK and RIN-NOXCNF-AC-SUS-BYK. For NOXCNFAC-SUS-BYK, there were large NOXCNF aggregates, and the network structure was not uniform. But for RIN-NOXCNFAC-SUS-BYK, the large NOXCNF aggregates disappeared, and the quality of network structures was improved. Therefore, the acid rinse enhanced the dispersion of NOXCNF in acetone.

3.5. Bulk Densities of Carbon Nanofiber Paper. The bulk density is one of the important parameters of carbon nanofiber paper. The thickness, weight, weight percentage, and density of carbon nanofiber paper are shown in Table 2. The bulk densities are plotted against the sample number in Figure 6. It can be seen that all the samples made from the upper suspension had higher bulk densities than those from the deposits. This is due to the close packing of individual nanofibers uniformly dispersed in the suspension. Bars 1, 2 , and 3 represent the samples made from the suspension of OXCNF in water, alcohol, and acetone, respectively. The bulk densities of these samples from the deposits decreased by following the order: water, alcohol, and acetone. The sample from the alcohol suspension has the lowest bulk 


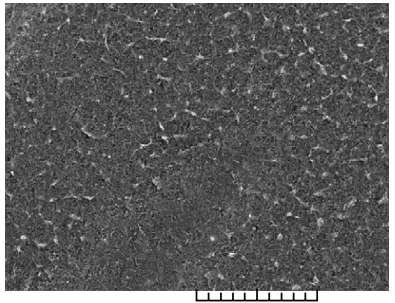

$50 \mu \mathrm{m}$

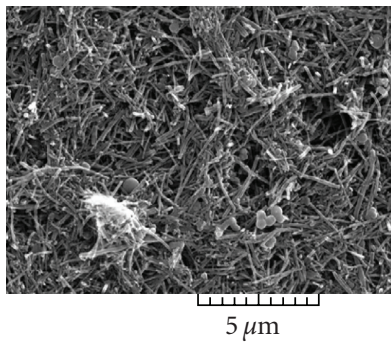

(a) OXCNF-WA-SUS
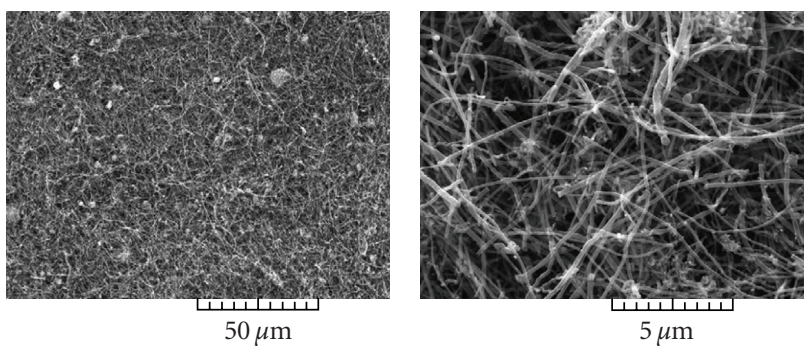

(b) OXCNF-AL-SUS

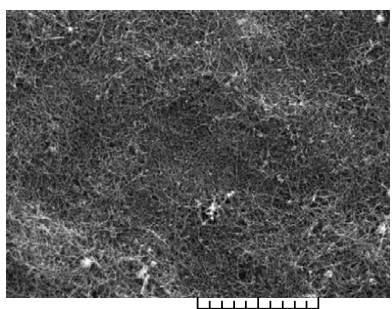

$50 \mu \mathrm{m}$

(c) OXCNF-AC-SUS
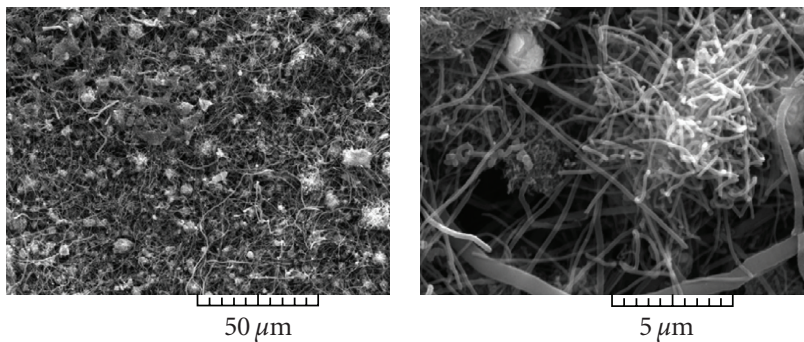

(d) OXCNF-WA-DEP
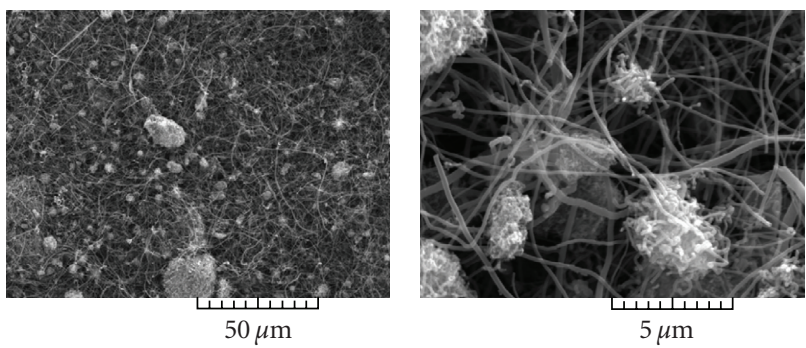

(e) OXCNF-AL-DEP

FIGURE 1: SEM images of carbon nanofiber paper: OXCNF-WASUS, OXCNF-AL-SUS, OXCNF-AC-SUS, OXCNF-WA-DEP, and OXCNF-AL-DEP.
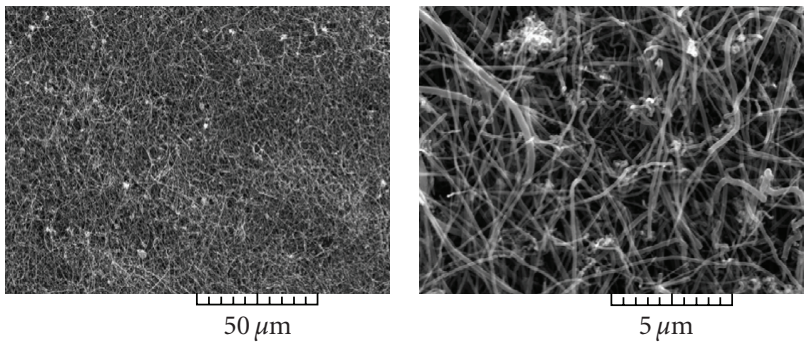

FIGURE 2: SEM images of carbon nanofiber paper: OXCNF-ACSUS-BYK.

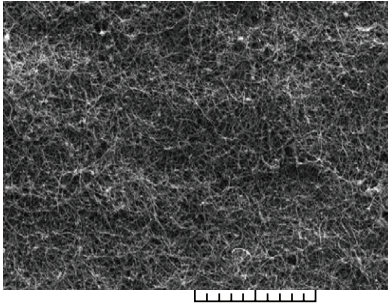

$50 \mu \mathrm{m}$

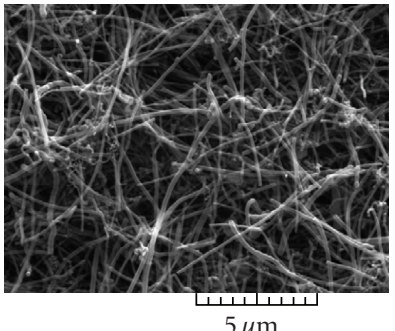

$5 \mu \mathrm{m}$ (a) RIN-OXCNF-AC-SUS-BYK
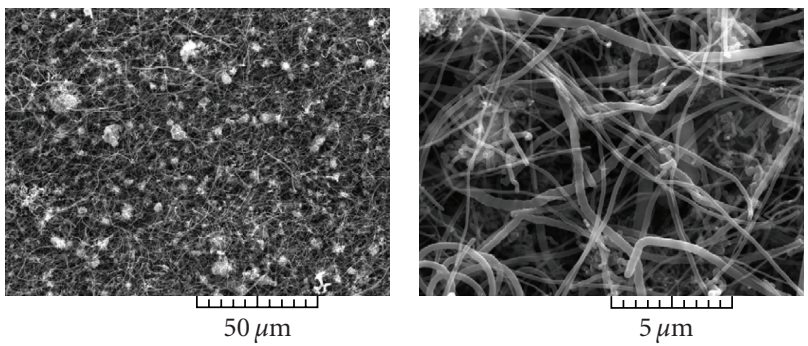

(b) RIN-OXCNF-AC-DEP-BYK

FIGURE 3: SEM images of carbon nanofiber paper: RIN-OXCNFAC-SUS-BYK and RIN-OXCNF-AC-DEP-BYK.

density. This agrees very well with the SEM images shown in Figure 1. Compared to Sample 3, BYK was used for Sample 4. In Sample 5, OXCNF was rinsed with the diluted nitric acid and dispersed with the aid of BYK. Both BYK and acid rinse improved the dispersion of OXCNFs in acetone. The same phenomenon was observed for the samples made from the OXCNF aqueous solutions by comparing Samples 1 and 6 . After the acid rinse, their bulk densities increased. For NOXCNF, the bulk densities of the samples from the deposits have no significant changes. However, the acid rinse increased their bulk densities for the samples from the suspension.

\section{Conclusions}

This paper systematically studied the processing-structure relationship of carbon nanofiber paper. It is clearly seen that the dispersion of carbon nanofibers in solvents played an important role in determining the network structures 
TABLE 2: Bulk densities of carbon nanofiber papers.

\begin{tabular}{|c|c|c|c|c|c|}
\hline Sample ID & Sample number & Thickness $(\mathrm{mm})$ & Weight (mg) & Weight percentage $\mathrm{e}^{(\mathrm{a})}(\mathrm{wt} \%)$ & Bulk density ${ }^{(\mathrm{b})}\left(\mathrm{g} / \mathrm{cm}^{3}\right)$ \\
\hline OXCNF-WA-SUS & \multirow{2}{*}{1} & 0.346 & 158 & 74.5 & 0.383 \\
\hline OXCNF-WA-DEP & & 0.149 & 54 & 25.5 & 0.304 \\
\hline OXCNF-AL-SUS & \multirow{2}{*}{2} & 0.563 & 141 & 69.5 & 0.210 \\
\hline OXCNF-AL-DEP & & 0.274 & 62 & 30.5 & 0.189 \\
\hline OXCNF-AC-SUS & \multirow{2}{*}{3} & 0.256 & 77 & 38.5 & 0.252 \\
\hline OXCNF-AC-DEP & & 0.768 & 123 & 61.5 & 0.134 \\
\hline OXCNF-AC-SUS-BYK & \multirow{2}{*}{4} & 0.384 & 125 & 60.7 & 0.272 \\
\hline OXCNF-AC-DEP-BYK & & 0.371 & 81 & 39.3 & 0.183 \\
\hline RIN-OXCNF-AC-SUS-BYK & \multirow{2}{*}{5} & 0.294 & 114 & 59.1 & 0.324 \\
\hline RIN-OXCNF-AC-DEP-BYK & & 0.288 & 79 & 40.9 & 0.231 \\
\hline RIN-OXCNF-WA-SUS & \multirow{2}{*}{6} & 0.237 & 121 & 61.1 & 0.426 \\
\hline RIN-OXCNF-WA-DEP & & 0.160 & 77 & 38.9 & 0.403 \\
\hline NOXCNF-AC-SUS-BYK & \multirow{2}{*}{7} & 0.845 & 134 & 67 & 0.133 \\
\hline NOXCNF-AC-DEP-BYK & & 0.461 & 66 & 33 & 0.120 \\
\hline RIN-NOXCNF-AC-SUS-BYK & \multirow{2}{*}{8} & 0.474 & 108 & 52.7 & 0.191 \\
\hline RIN-NOXCNF-AC-DEP-BYK & & 0.614 & 97 & 47.3 & 0.132 \\
\hline
\end{tabular}

Note: (a) Total weight of carbon nanofibers from the suspension and deposit; (b) sample diameter $39 \mathrm{~mm}$.

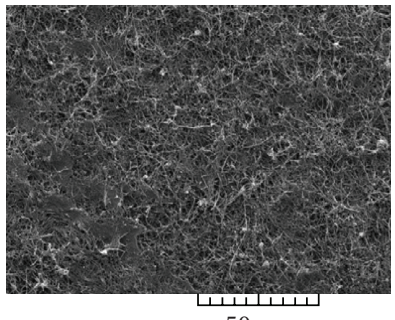

$50 \mu \mathrm{m}$

(a) RIN-OXCNF-WA-SUS
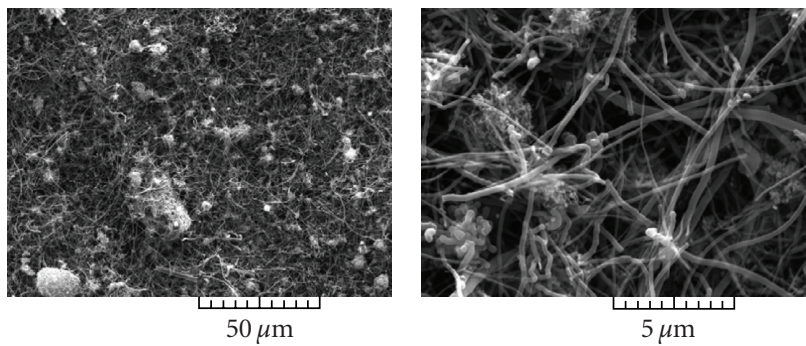

(b) RIN-OXCNF-WA-DEP

FIGURE 4: SEM images of carbon nanofiber paper: RIN-OXCNFWA-SUS and RIN-OXCNF-WA-DEP.

of carbon nanofiber paper. The good dispersion led to close packing of carbon nanofibers, which formed the uniform network structure of the paper with a higher bulk density. The variations in the dispersion quality caused the changes in the network structures and densities of carbon nanofiber paper. The types of solvents, dispersant, acid rinse, and types of carbon nanofibers significantly affected the dispersion quality. It has been found that OXCNFs were

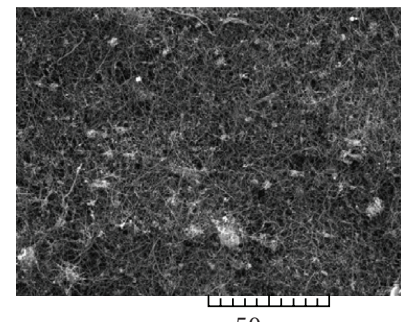

$50 \mu \mathrm{m}$

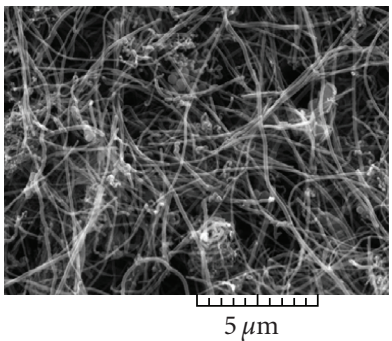

(a) NOXCNF-AC-SUS-BYK
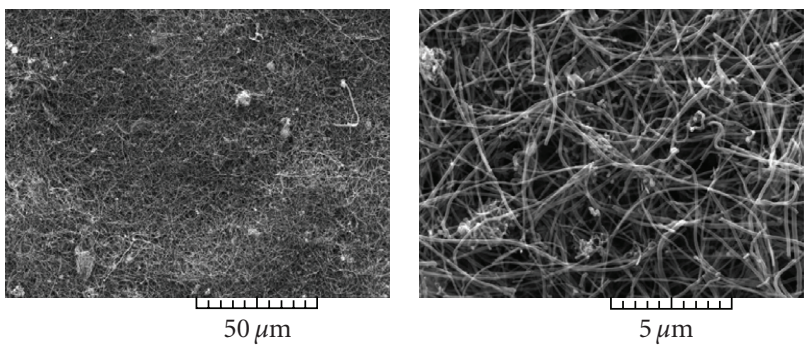

(b) RIN-NOXCNF-AC-SUS-BYK

FIGURE 5: SEM images of carbon nanofiber paper: NOXCNF-ACSUS-BYK and RIN-NOXCNF-AC-SUS-BYK.

easily dispersed in water and alcohol but not well in acetone due to the functional groups on the fiber surface. Although there were few functional groups on NOXCNFs, they were easily dispersed in acetone with the aid of dispersant. In addition, the treatment with diluted nitric acid improved the dispersion in the solvents. Therefore, the network structure of carbon nanofiber paper can be controlled and optimized by choosing appropriate processing parameters. 


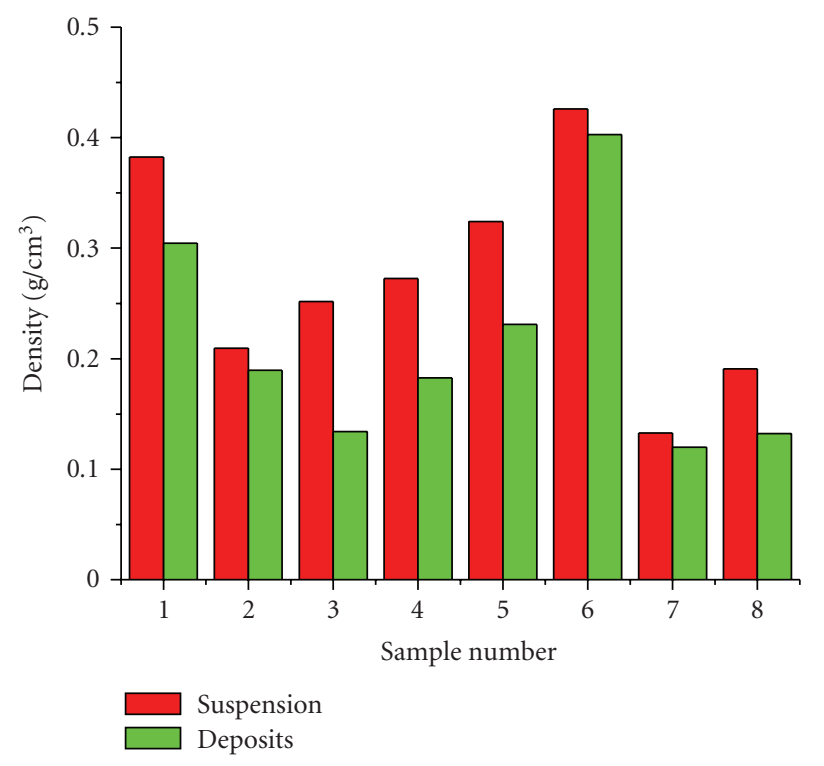

FIgURE 6: Bulk densities of carbon nanofiber papers.

\section{Acknowledgments}

This material is based upon work supported by the National Science Foundation's nanomanufacturing program under Grant no. 0757302 managed by program manager, Dr. Shaochen Chen. The acknowledgment is also made to Florida Center for Advanced Aero-Propulsion (FCAAP) program under Grant no. FSU\#218007-530-024809-R010689. Any opinions, findings, and conclusions or recommendations expressed in this material are those of the authors and do not necessarily reflect the views of the National Science Foundation.

\section{References}

[1] A. K.-T. Lau and D. Hui, "The revolutionary creation of new advanced materials - carbon nanotube composites," Composites Part B, vol. 33, no. 4, pp. 263-277, 2002.

[2] E. T. Thostenson, Z. Ren, and T.-W. Chou, "Advances in the science and technology of carbon nanotubes and their composites: a review," Composites Science and Technology, vol. 61, no. 13, pp. 1899-1912, 2001.

[3] D. Qian, E. C. Dickey, R. Andrews, and T. Rantell, "Load transfer and deformation mechanisms in carbon nanotubepolystyrene composites," Applied Physics Letters, vol. 76, no. 20, pp. 2868-2870, 2000.

[4] D. Qian and E. C. Dickey, "In-situ transmission electron microscopy studies of polymer-carbon nanotube composite deformation," Journal of Microscopy, vol. 204, no. 1, pp. 3945, 2001.

[5] P. M. Ajayan, L. S. Schadler, C. Giannaris, and A. Rubio, "Single-walled carbon nanotube-polymer composites: strength and weakness," Advanced Materials, vol. 12, no. 10, pp. 750-753, 2000.

[6] L. S. Schadler, S. C. Giannaris, and P. M. Ajayan, "Load transfer in carbon nanotube epoxy composites," Applied Physics Letters, vol. 73, no. 26, pp. 3842-3844, 1998.
[7] L. Jin, C. Bower, and O. Zhou, "Alignment of carbon nanotubes in a polymer matrix by mechanical stretching," Applied Physics Letters, vol. 73, no. 9, pp. 1197-1199, 1998.

[8] C. Bower, R. Rosen, L. Jin, J. Han, and O. Zhou, "Deformation of carbon nanotubes in nanotube-polymer composites," Applied Physics Letters, vol. 74, no. 22, pp. 3317-3319, 1999.

[9] Z. Ounaies, C. Park, K. E. Wise, E. J. Siochi, and J. S. Harrison, "Electrical properties of single wall carbon nanotube reinforced polyimide composites," Composites Science and Technology, vol. 63, no. 11, pp. 1637-1646, 2003.

[10] C. Stéphan, T. P. Nguyen, M. Lamy de la Chapelle, S. Lefrant, C. Journet, and P. Bernier, "Characterization of singlewalled carbon nanotubes-PMMA composites," Synthetic Metals, vol. 108, no. 2, pp. 139-149, 2000.

[11] M. S. P. Shaffer and A. H. Windle, "Fabrication and characterization of carbon nanotube/poly(vinyl alcohol) composites," Advanced Materials, vol. 11, no. 11, pp. 937-941, 1999.

[12] J. Sandler, M. S. P. Shaffer, T. Prasse, W. Bauhofer, K. Schulte, and A. H. Windle, "Development of a dispersion process for carbon nanotubes in an epoxy matrix and the resulting electrical properties," Polymer, vol. 40, no. 21, pp. 5967-5971, 1999.

[13] X. Y. Gong, J. Liu, S. Baskaran, R. D. Voise, and J. S. Young, "Surfactant-assisted processing carbon nanotube/polymer composites," Chemistry of Materials, vol. 12, no. 4, pp. 10491052, 2000.

[14] Z. Jin, K. P. Pramoda, G. Xu, and S. H. Goh, "Dynamic mechanical behavior of melt-processed multi-walled carbon nanotube/poly(methyl methacrylate) composites," Chemical Physics Letters, vol. 337, no. 1-3, pp. 43-47, 2001.

[15] K. Lozano and E. V. Barrera, "Nanofiber-reinforced thermoplastic composites-I: thermoanalytical and mechanical analyses," Journal of Applied Polymer Science, vol. 79, no. 1, pp. 125-133, 2001.

[16] K. Lozano, J. Bonilla-Rios, and E. V. Barrera, "A study on nanofiber-reinforced thermoplastic composites (II): investigation of the mixing rheology and conduction properties," Journal of Applied Polymer Science, vol. 80, no. 8, pp. 11621172, 2001.

[17] R. Haggenmueller, H. H. Gommans, A. G. Rinzler, J. E. Fischer, and K. I. Winey, "Aligned single-wall carbon nanotubes in composites by melt processing methods," Chemical Physics Letters, vol. 330, no. 3-4, pp. 219-225, 2000.

[18] Z. J. Jia, Z. Y. Wang, C. L. Xu, et al., "Study on poly(methyal methacrylate)/carbon nanotube composites," Materials Science and Engineering A, vol. 271, no. 1-2, pp. 395-400, 1999.

[19] C. Park, Z. Ounaies, K. A. Watson, et al., "Dispersion of single wall carbon nanotubes by in situ polymerization under sonication," Chemical Physics Letters, vol. 364, no. 3-4, pp. 303-308, 2002.

[20] F. H. Gojny, M. H. G. Wichmann, B. Fiedler, W. Bauhofer, and K. Schulte, "Influence of nano-modification on the mechanical and electrical properties of conventional fibrereinforced composites," Composites Part A, vol. 36, no. 11, pp. 1525-1535, 2005.

[21] F. H. Gojny, M. H. G. Wichmann, U. Köpke, B. Fiedler, and K. Schulte, "Carbon nanotube-reinforced epoxy-composites: enhanced stiffness and fracture toughness at low nanotube content," Composites Science and Technology, vol. 64, no. 15, pp. 2363-2371, 2004.

[22] J. Gou, S. O'Braint, H. Gu, and G. Song, "Damping augmentation of nanocomposites using carbon nanofiber paper," Journal of Nanomaterials, vol. 2006, Article ID 32803, 7 pages, 2006. 
[23] J. Gou, "Single-walled nanotube bucky paper and nanocomposite," Polymer International, vol. 55, no. 11, pp. 1283-1288, 2006.

[24] J. Gou, Z. Liang, and B. Wang, "Experimental design and optimization of dispersion process for single-walled carbon nanotube bucky paper," International Journal of Nanoscience, vol. 3, no. 3, pp. 293-307, 2004. 

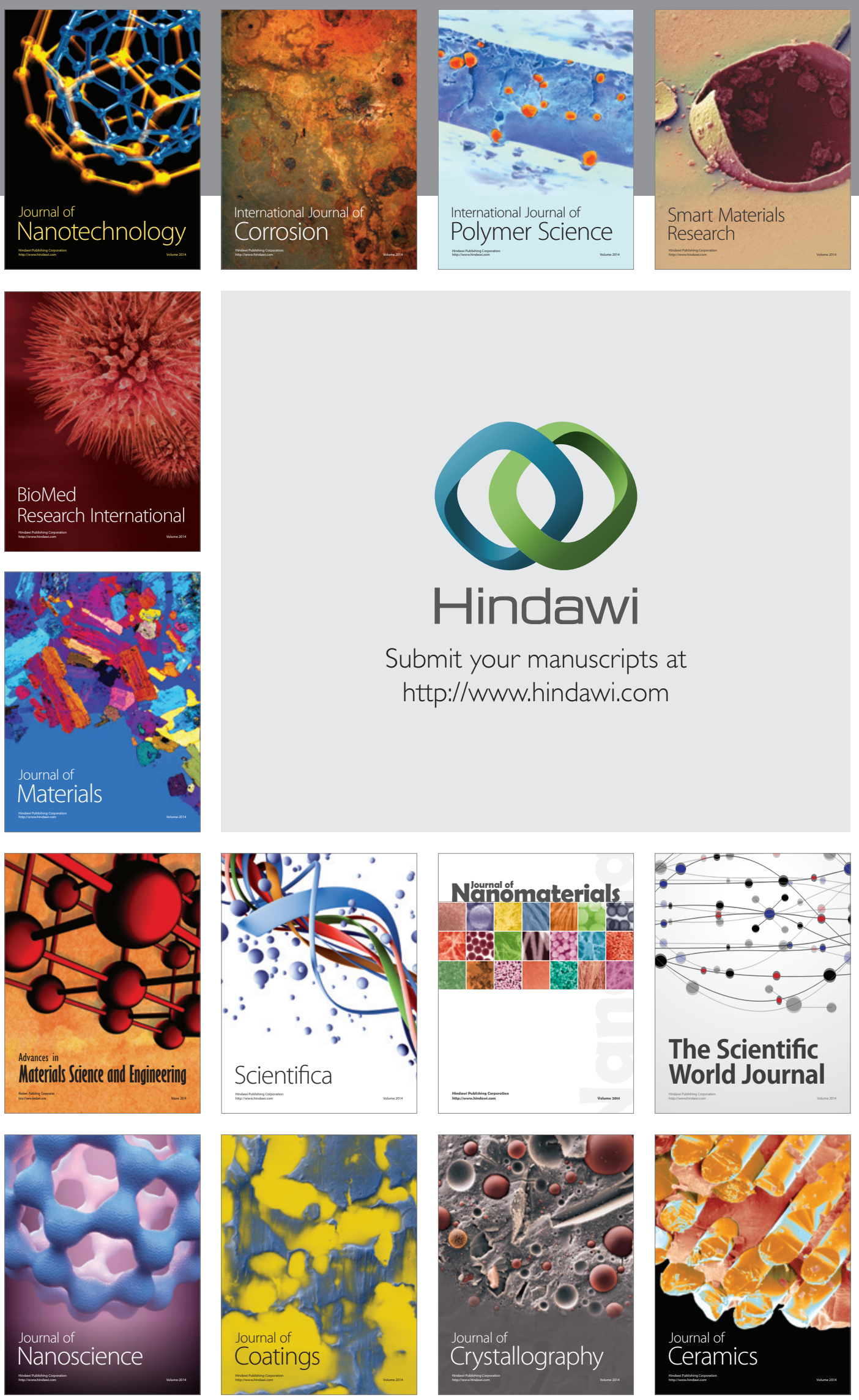

The Scientific World Journal

Submit your manuscripts at

http://www.hindawi.com

\section{World Journal}

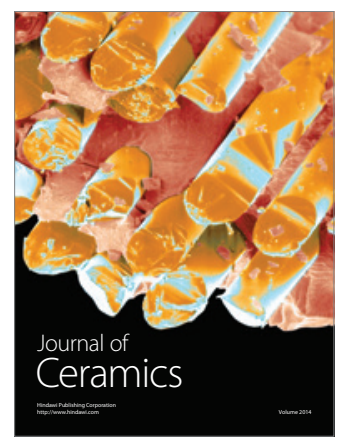

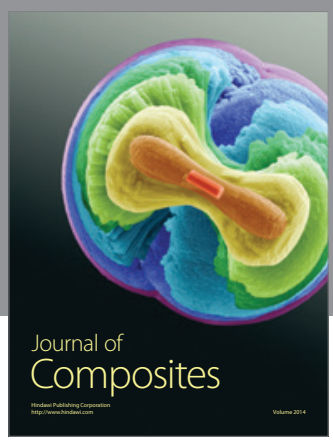
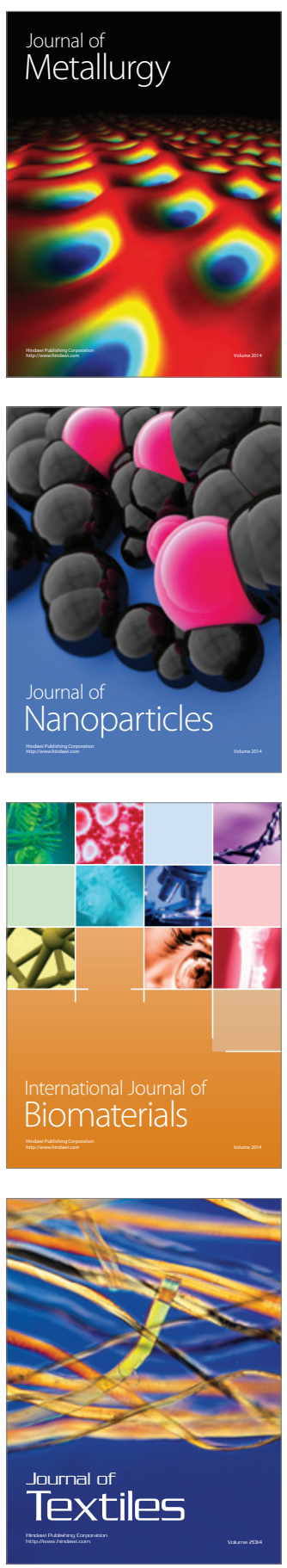